\title{
Синтез геополимеров на основе золы уноса с применением механоактивации
}

Калинкин А.М., Гуревич Б.И., Калинкина Е.В., Семушин В.В., Залкинд О.А.

Институт химии и технологии редких элементов и минерального сырья им. И.В. Тананаева ФИЦ КНЦ PAH, Anamumbl, a.kalinkin@ksc.ru

Аннотация. Изучено влияние механоактивации в центробежно-планетарной мельнице низкокальциевой (3.67 мас. \% СaO) высокожелезистой (19.3 мас. \% $\mathrm{Fe}_{2} \mathrm{O}_{3}$ ) золы уноса ТЭЦ на физико-механические свойства геополимеров, синтезированных на ее основе с применением в качестве щелочного агента жидкого стекла. Показано, что механоактивация существенно повышает реакционную способность золы уноса в геополимерном синтезе и прочность при сжатии геополимеров. На основе механоактивированной низкокальциевой высокожелезистой золы уноса и жидкого стекла с модулем 1.43 могут быть получены геополимеры с прочностью при сжатии 53-78 МПа в возрасте 28-180 сут.

Ключевые слова: зола уноса, геополимеры, механоактивация.

\section{Synthesis of geopolymers based on fly ash using mechanical activation}

\author{
Kalinkin A.M., Gurevich B.I., Kalinkina E.V., Semushin V.V., Zalkind O.A. \\ Tananaev Institute of Chemistry-Subdivision of the Federal Research Centre KSC RAS, Apatity, \\ a.kalinkin@ksc.ru
}

Abstract. The effect of mechanical activation in a centrifugal planetary mill of low-calcium ( $3.67 \mathrm{wt} . \% \mathrm{CaO})$ high-iron (19.3 wt. \% $\mathrm{Fe}_{2} \mathrm{O}_{3}$ ) fly ash from thermal power plant on the physicomechanical properties of geopolymers synthesized based on it using liquid glass has been studied. It has been shown that mechanical activation significantly increases the reactivity of ash in geopolymer synthesis and the compressive strength of geopolymers. Based on mechanically activated low-calcium high-iron fly ash and liquid glass with a modulus of 1.43 , geopolymers with compressive strength of 53-78 MPa at the age of 28-180 days can be prepared.

Key words: fly ash, geopolymers, mechanical activation.

\section{Введение}

Разведанные запасы месторождений угля, относящегося к каустобиолитам (горючие полезные ископаемые с большим содержанием углерода органического происхождения), составляют более 3300 млрд. т, а его общие ресурсы мире оцениваются в 16-20 трлн. т (Юдович и др., 2015). Несмотря на активное развитие атомной энергетики с середины 20 века, вклад угля в производимую электроэнергию остается весьма большим: в мире - 40 \%, в России - 25 \% (Любимова и др., 2019). Высокие температуры, при которых происходит сжигание органической части угля на теплоэлектростанциях (1500-1800 $\left.{ }^{\circ} \mathrm{C}\right)$, приводят к термолизу и плавлению его неорганических минеральных компонентов с образованием твердых дисперсных отходов угольной энергетики - золы уноса и шлака. Минеральный состав золошлаковых отходов представлен в основном стеклофазой, подобной вулканическому стеклу, а также кварцем, муллитом, магнетитом и др. Если в 2005 г. общемировой объем твердых отходов угольных теплоэлектростанций составил примерно 500 млн. т, то в 2015 г. - уже около 750 млн. т, при этом в среднем их утилизация составляет лишь 25 \% (Yao et al., 2015). B Pocсии количество золошлаковых отходов, занимающих значительные территории и неблагоприятно влияющих на экологическую обстановку, оценивается в 1.5 млрд. т (Делицин и др, 2012). Таким образом, в результате деятельности предприятий угольной энергетики образовались техногенные месторождения зол и шлаков, которые непрерывно пополняются.

Среди большого количества предложенных вариантов утилизации отходов сжигания угля (Yao et al., 2015; Gollakota et al., 2019) главным является строительная индустрия, в которой высококальциевые золы и шлаки могут применяться в качестве вяжущих, а низкокальциевые - как мелкозернистые заполнители бетонов. В последние годы интенсивные исследования проводятся еще в 
одном направлении - использовании низкокальциевых зол для синтеза геополимерных материалов. Геополимеры относятся к вяжущим щелочной активации, которые получают при взаимодействии алюмосиликатного сырья со щелочным агентом (растворы гидроксида натрия, жидкое стекло). Они рассматриваются в качестве альтернативы портландцементу и имеют большой потенциал для применения в строительной отрасли как эффективные и долговечные цементы и бетоны (Davidovits, 2017; Provis, 2018). Кроме того, геополимеры обладают комплексом ценных физико-химических свойств, что позволяет создавать на их основе материалы для огне- и теплозащиты, очистки сточных вод, матрицы для иммобилизации тяжелых металлов и радиоактивных отходов и др. (Mehta et al., 2016; Tang et al., 2019; Luukkonen et al., 2019). Свойства геополимеров зависят от состава золы, который, в свою очередь, определяется составом сжигаемого угля. В данной работе исследованы физико-механические характеристики геополимеров на основе механоактивированной низкокальциевой высокожелезистой золы уноса с применением в качестве щелочного агента жидкого стекла.

\section{Экспериментальные результаты и их обсуждение}

Геополимеры получали с использованием золы уноса, отобранной с электрофильтров Апатитской ТЭЦ (Мурманская обл.) методом гидроудаления. По химическому составу зола является кислой (содержание $\mathrm{CaO}$ менее 4 \%) и фактически наполовину состоит из оксида кремния. Содержания оксидов алюминия и железа в золе примерно одинаковы и составляют по 19-20 \% (таблица). Следует отметить, что обычно низкокальциевые золы ТЭЦ содержат не более 10 мас. \% $\mathrm{Fe}_{2} \mathrm{O}_{3}$.

Таблица. Химический состав золы уноса, мас. \%.

Table. The chemical composition of the fly ash, wt. \%.

\begin{tabular}{|c|c|c|c|c|c|c|c|c|c|c|c|}
\hline $\mathrm{SiO}_{2}$ & $\mathrm{Al}_{2} \mathrm{O}_{3}$ & $\mathrm{Fe}_{2} \mathrm{O}_{3}$ & $\mathrm{CaO}$ & $\mathrm{MgO}$ & $\mathrm{Na}_{2} \mathrm{O}$ & $\mathrm{K}_{2} \mathrm{O}$ & $\mathrm{TiO}_{2}$ & $\mathrm{MnO}$ & $\mathrm{SO}_{3}$ & $\mathrm{C}$ & П.П.П. \\
\hline 49.10 & 19.69 & 19.30 & 3.67 & 3.34 & 0.71 & 1.23 & 0.51 & 0.23 & 0.42 & 0.89 & 2.43 \\
\hline
\end{tabular}

Минеральный состав золы представлен алюмосиликатной стеклофазой в виде частиц шарообразной формы (микросфер) и спекшихся минеральных частиц неправильной формы с развитой поверхностью (рис. 1 а). Кристаллические фазы золы - $\alpha$-кварц, муллит, магнетит и гематит. По гранулометрическому составу зола является тонкодисперсной, содержание фракции менее 33 мкм составляет $75 \%$.

ИК-спектры снимались на Фурье ИК спектрометре Nicolet 6700 FTIR в таблетках бромида калия. Исследования методом сканирующей электронной микроскопии (СЭМ) проводили с помощью микроскопа LEO 420 (Karl Zeis).

Механическую активацию (MA) золы проводили в лабораторной центробежно-планетарной мельнице АГО-2 (Аввакумов и др., 2009) в воздушной среде при центробежном факторе 40 g; продолжительность МА - до 400 с. В качестве мелющих тел использовали стальные шары диаметром
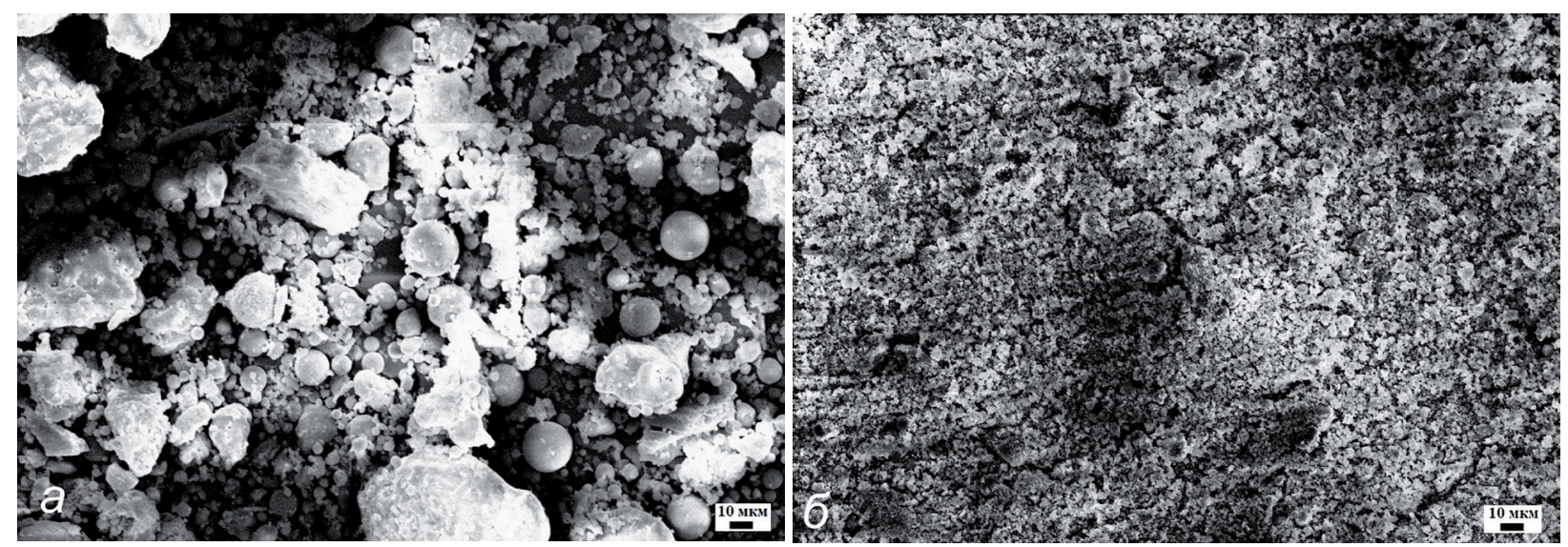

Рис. 1. СЭМ изображения исходной золы уноса (а) и золы уноса после 180 с механоактивации (б).

Fig. 1. SEM images of the initial fly ash (a) and fly ash after $180 \mathrm{~s}$ of mechanical activation (б). 


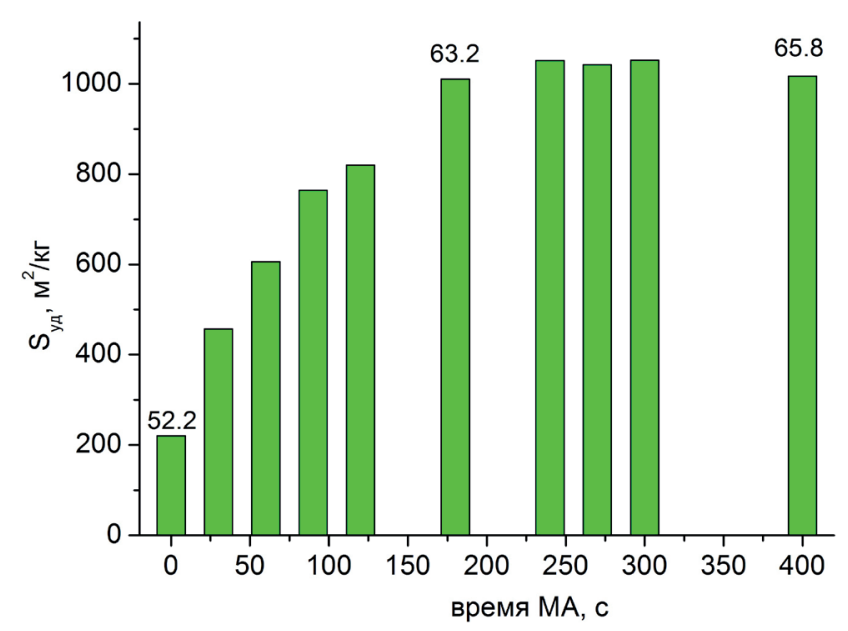

Рис. 2. Зависимость удельной поверхности золы от продолжительности МА. Для исходной золы, а также для золы после 180 и 400 с МА указано содержание стеклофазы (мас. \%).

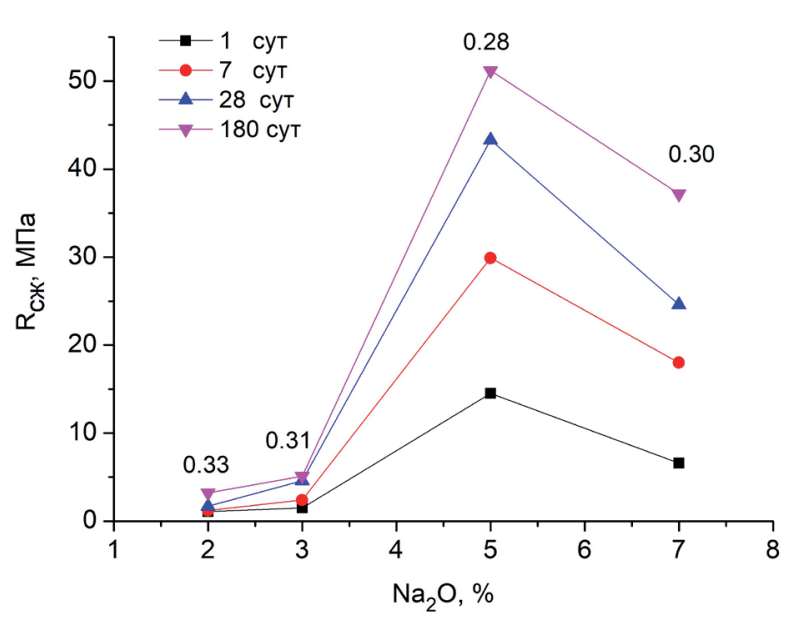

Рис. 3. Зависимость прочности при сжатии $\left(\mathrm{R}_{\text {сж }}\right)$ геополимеров, полученных с использованием жидкого стекла № 1, в возрасте 1, 7, 28 и 180 сут от содержания жидкого стекла. Время МА золы - 180 с.

Fig. 2. The dependence of the specific surface area of the Fig. 3. The dependence of the compressive strength $\left(\mathrm{R}_{\mathrm{c \varkappa}}\right)$ ash on the duration of mechanical activation. For the initial of geopolymers prepared using ash and water glass $\mathrm{N}^{\circ} 1$, ash, as well as for the ash after 180 and 400 s of mechani- cured for 1, 7, 28, and 180 days, on the content of water cal activation, the glass phase content (wt.\%) is indicated. glass. Ash was mechanically activated for $180 \mathrm{~s}$.

8 мм при отношении массы шаров к массе загрузки 6:1. Удельную поверхность $\left(\mathrm{S}_{\text {уд }}\right)$ порошков измеряли методом воздухопроницаемости. Исходную золу и механоактивированную золу (МА-золу) анализировали на содержание стеклофазы методом селективного кислотного растворения золы в 1 \%-ном водном растворе HF (Singh et al., 2019). Для этого 0.7 г золы добавляли к 70 мл $1 \%$ раствора НF в тефлоновом стакане и перемешивали в течение 4.5 ч при температуре $20-22^{\circ} \mathrm{C}$. Затем суспензию фильтровали, не растворившийся остаток на фильтре промывали дистиллированной водой и сушили при $105^{\circ} \mathrm{C} 12$ ч. Общее содержание стеклофазы определяли по разнице между навеской золы и массой не растворившегося остатка.

При синтезе геополимеров в качестве щелочного активизатора применяли жидкое стекло с модулем 1.43 (№ 1) и 3.18 (№ 2). Порошки исходной или МА-золы вручную смешивали с жидким стеклом, количество которого рассчитывали как мас.\% $\mathrm{Na}_{2} \mathrm{O}$ в стекле по отношению к массе сухой золы. Для получения теста пластичной консистенции добавляли необходимое количество воды. Водотвердое отношение $(\mathrm{B} / \mathrm{T})$ рассчитывалось как отношение суммарной массы воды в тесте к массе золы. Из теста изготавливали кубики размером $1.41 \times 1.41 \times 1.41 \mathrm{~cm}$, которые твердели во влажных условиях (относительная влажность $>95$ \%) при температуре $20-22^{\circ} \mathrm{C}$. Испытание образцов на сжатие проводились на прессе марки ПГМ-100МГ4А. Величину прочности при сжатии для каждого состава определяли как среднее арифметическое для трех параллельных образцов.

При МА золы происходит уменьшение размеров частиц и разрушение микросфер, причем после 180 с МА по данным СЭМ практически все микросферы разрушены (рис. 1 б).

Нами ранее показано, что в ходе механической обработки высокожелезистой золы в планетарной мельнице наряду с диспергированием происходит уширение рефлексов кварца, муллита, магнетита и гематита в рентгенограммах, связанное с уменьшением размеров кристаллитов и ростом микродеформаций решеток (Калинкин и др., 2018). Поэтому механоактивированные минералы в составе золы, в принципе, также могут оказаться реакционноспособными, что подтверждается данными, приведенными на рисунке 2. Под влиянием МА содержание стеклофазы, под которой понимается общее количество реакционноспособных компонентов как стеклофазы, так и механоактивированных минералов золы, возрастает от 52.2 \% в исходной золе до 65.8 \% в золе после 400 с МА. 

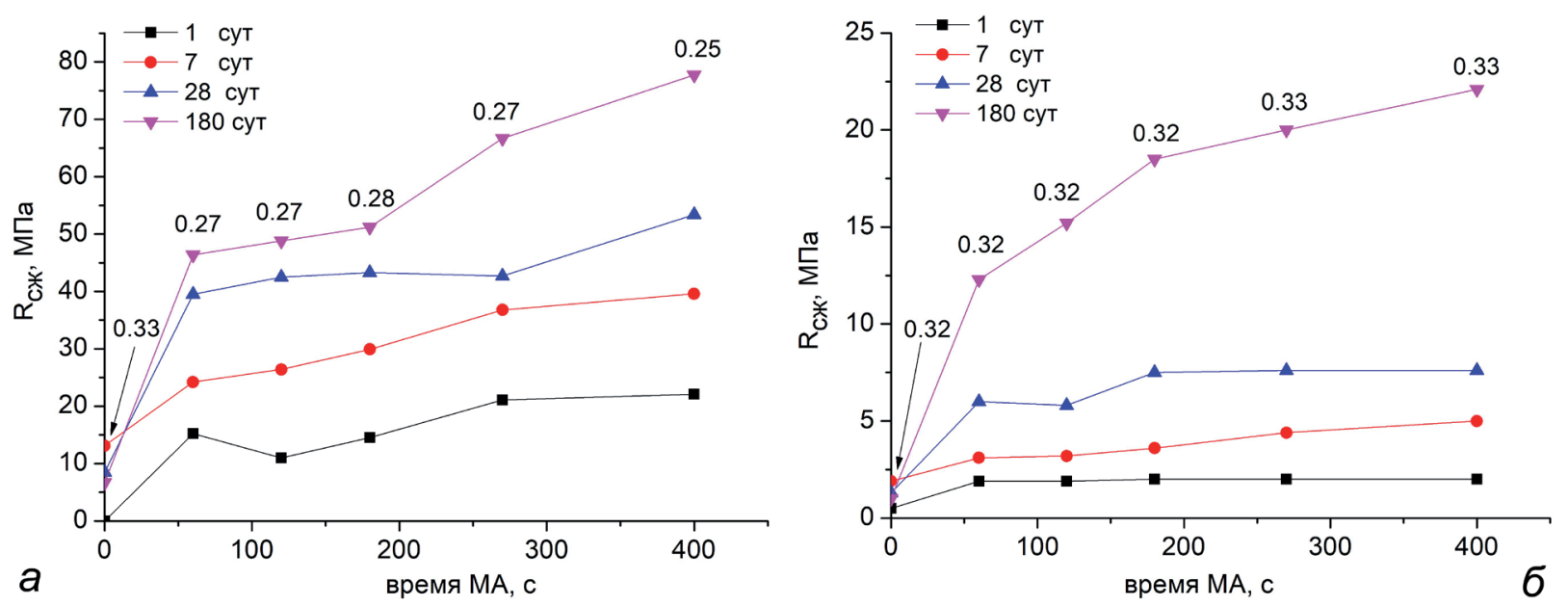

Рис. 4. Зависимость прочности при сжатии $\left(\mathrm{R}_{\text {сж }}\right)$ геополимеров, полученных с использованием жидкого стекла № 1 (а) и № 2 (б), в возрасте 1, 7, 28 и 180 сут от продолжительности МА. Содержание жидкого стекла - 5 мас. \% $\mathrm{Na}_{2} \mathrm{O}$. Числа на графике соответствуют отношению В/Т.

Fig. 4. The dependence of the compressive strength $\left(\mathrm{R}_{\text {сж }}\right)$ of geopolymers prepared using water glass No. 1 (a) and No. 2 (б) cured for 1, 7, 28, and 180 days on the duration of mechanical activation. The content of liquid glass is 5 wt. \% $\mathrm{Na}_{2} \mathrm{O}$. Numbers in the figure correspond to water to solid ratio.

На рисунке 2 приведена также зависимость удельной поверхности золы от времени МА. Максимальная удельная поверхность достигается после 250-300 с МА, при этом по отношению к исходной золе она возрастает в 4.8 раза; затем вследствие усиления агрегации частиц $\mathrm{S}_{\text {уд }}$ несколько снижается.

Прочности при сжатии $\left(\mathrm{R}_{\text {сж) }}\right)$ геополимеров, полученных с применением золы, механоактивированной 180 с, и жидкого стекла № 1 в зависимости от содержания жидкого стекла в интервале от 2 до 7 мас. \% $\mathrm{Na}_{2} \mathrm{O}$ представлены на рис. 3. Числа на графике соответствуют отношению В/Т. Отчетливо видно, что для всех сроков твердения максимальные значения $\mathrm{R}_{\text {сж }}$ соответствуют 5 мас. \% $\mathrm{Na}_{2} \mathrm{O}$. Дальнейшие эксперименты по синтезу геополимеров проводились при указанном расходе жидких стекол.

Сравнение ИК спектров исходной золы и геополимеров в 28-сут возрасте на основе исходной и МА-золы (не приведены) показывает, что в результате взаимодействия золы с жидким стеклом происходит смещение полосы антисимметричных валентных колебаний T-O-Si (T = Si, Al) в область низких частот. Этот частотный сдвиг свидетельствует об образовании N-A-S-H геля (натрий содержащего алюмосиликатного гидрогеля) - продукта щелочной активации золы, цементирующего геополимер. Смещение полосы объясняется замещением Si на Al в кремнийкислородных тетраэдрах, ростом содержания тетраэдрически координированного алюминия, а также уменьшением степени полимеризации силикатного (алюмосиликатного) каркаса исходной золы (Lee et al., 2002; Fernandez-Jimenez et al., 2005; Nath et al., 2016; Rozek et al., 2018). Для образцов на основе МА-золы в сравнении с образцом на основе исходной золы это сдвиг выражен в большей степени, что указывает на существенное повышение реакционной способности золы в отношении жидкого стекла в результате МА и, соответственно, на более глубокое протекание геополимерного синтеза.

Анализ прочности при сжатии геополимеров, синтезированных с применением жидкого стекла № 1(рис. 4 а) и № 2 (рис. 4 б) позволил выявить следующие тенденции. Для обоих жидких стекол с увеличением времени МА золы величина $\mathrm{R}_{\text {сж }}$ растет, причем этот рост отчетливее проявляется при длительном твердении (180 сут) по сравнению с образцами в меньшем возрасте.

МА золы в течение 60 с позволяет получить геополимеры с прочностью в 28-сут возрасте, превышающей аналогичную величину для геополимеров на исходной золе в 4.6 раза (для обоих жидких стекол). При более длительной обработке золы в мельнице эффективность МА падает. Для сравнения: увеличение времени МА до 400 с дает прирост прочности в возрасте 28 сут по отношению к соответствующим геополимерам, синтезированным на основе золы после 60 с МА, только в 1.3 и в 1.4 раза для жидких стекол № 1 и № 2 соответственно. 
Повышение модуля жидкого стекла с 1.43 (№ 1) до 3.18 (№ 2) приводит к существенному падению прочности геополимеров при равных продолжительностях МА золы и сроках твердения. МА золы в течение 60-400 с позволяет получить геополимеры с использованием жидкого стекла № 1 в возрасте 28 сут с прочностью 39-53 МПа (рис. 4 а). Для аналогичных геополимеров, синтезированных с применением жидкого стекла № 2, соответствующий интервал составляет 6-8 МПа (рис. 4 б). Снижение прочности геополимеров на высокомодульном стекле, по-видимому, объясняется его меньшей реакционной способностью по отношению к золе в сравнении со стеклом № 1.

Таким образом, на основе механоактивированной низкокальциевой высокожелезистой золы уноса Апатитской ТЭЦ и жидкого стекла с модулем 1.43 могут быть получены геополимеры с прочностью при сжатии 53-78 МПа в возрасте 28-180 сут. Дальнейшие исследования будут направлены на поиск оптимальных составов композиций, включая варьирование модуля жидкого стекла, и температурных режимов геополимерного синтеза.

Работа выполнена в рамках темы НИР ИХТРЭМС КНЦ РАН № 0226-2019-0068.

\section{Литература}

1. Аввакумов Е.Г., Гусев А.А. Механические методы активации в переработке природного и техногенного сырья. Новосибирск. Изд-во: Гео. 2009. 155 с.

2. Делицын Л.М., Ежова Н.Н., Власов А.С., Сударева С.В. // Экология промышл. произв. 2012. № 4. С. 15-26.

3. Калинкин А.М., Гуревич Б.И., Калинкина Е.В., Залкинд О.А. О гидратации механоактивированной низкокальциевой золы ТЭС. Химия в инт. уст. развития. 2018. Т. 26. № 4. С. 395-402.

4. Любимова Н.Г., Линник Ю.Н. Конкурентоспособность угольной генерации в России // Уголь. 2019. № 5. С. 34-38.

5. Юдович Я.Э., Кетрис М.П. Неорганическое вещество углей. М.-Берлин: Директ-Медиа. 2015. 423 с.

6. Davidovits J. Geopolymers: ceramic-like inorganic polymers // J. Ceram. Sci. Technol. 2017. V. 8. P. 335-349. DOI: 10.4416/JCST2017-00038.

7. Fernandez-Jimenez A., Palomo A. Mid-infrared spectroscopic studies of alkali-activated fly ash structure. // Microp. Mesop. Mater. 2005. V. 86. P. 207-214. Doi.org/10.1016/j.micromeso.2005.05.057.

8. Gollakota A.R.K., Volli V., Shu C.-M. Progressive utilisation prospects of coal fly ash: A review // Science of the Total Environment 2019. V. 672. P. 951-989. Doi.org/10.1016/j.scitotenv.2019.03.337.

9. Lee W.K.W., van Deventer J.S.J. Structural reorganisation of class F fly ash in alkaline silicate solutions // Colloids and Surfaces A: Physicochem. Eng. Aspects. 2002. V. 211. P. 49-66. Doi.org/10.1016/S09277757(02)00237-6.

10. Luukkonen T. et al. Application of alkali-activated naterials for water and wastewater treatment: a review // Rev. Environ. Sci. Biotechnol. 2019. V. 18. P. 271-297. Doi.org/10.1007/s11157-019-09494-0.

11. Mehta A, Siddique R. An Overview of geopolymers derived from industrial by-products // Constr. Build. Mater. 2016. V. 127. P. 183-198. Doi.org/10.1016/j.conbuildmat.2016.09.136.

12. Nath S.K., Maitra S., Mukherjee S., Kumar Sanjay. Microstructural and morphological evolution of fly ash based geopolymers // Constr. Build. Mater. 2016. V. 111. P. 758-765. Doi.org/10.1016/j.conbuildmat.2016.02.106.

13. Provis J.L. Alkali-activated materials // Cem. Concr. Res. 2018. V. 114. P. 40-48. Doi.org/10.1016/j.cemconres.2017.02.009.

14. Rozek P., Krol M., Mozgawa W. Spectroscopic studies of fly ash-based geopolymers // Spectrochim. Acta A. Mol. Biomol. Spectrosc. 2018. V. 198. P. 283-289. Doi.org/10.1016/j.saa.2018.03.034.

15. Singh G.V.P.B., Subramaniam K.V.L. Effect of active components on strength development in alkali-activated low calcium fly ash cements // J. Sustain. Cem. Based Mater. 2019. V. 8. № 1. P. 1-19. Doi.org/10.1080/216 50373.2018.1520657.

16. Tang Z., Li W., Hu Y., Zhou J.L., Tam V.W.Y. Review on designs and properties of multifunctional alkaliactivated materials (AAMs) // Constr. Build. Mater. 2019. V. 200. P. 474-489. Doi.org/10.1016/j.conbuildmat.2018.12.157.

17. Yao Z.T. et al. A comprehensive review on the applications of coal fly ash // Earth-Science Reviews. 2015. V. 141. P. 105-121. Dx.doi.org/10.1016/j.earscirev.2014.11.016. 